\title{
ROR $\gamma$ is dispensable for the development of intestinal mucosal T cells
}

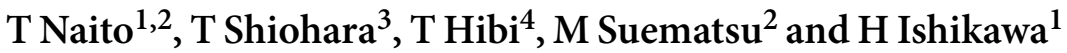

To examine the origin of intestinal mucosal T cells and, in particular, unconventional CD8 $\alpha \alpha^{+} \mathrm{T}$ cells, we have undertaken a thorough analysis of the gut immune compartment in euthymic and athymic mice carrying either wild-type or mutant transcription factor retinoic acid-related orphan receptor- $\gamma \mathrm{t}(\mathrm{ROR} \gamma \mathrm{t})$. We identified a previously unrealized complexity of gut cryptopatch (CP) cells that challenges the previous assertion that CP cells comprise ROR $\gamma$ t-expressing adult counterparts of fetal lymphoid tissue inducer (Lti) cells. We showed that many CP cells express intermediate T cell differentiation markers, whether or not they express ROR $\gamma \mathrm{t}$, and found that CPs are not completely dependent on ROR $\gamma \mathrm{t}$, as previously reported, but merely fewer in number in the ROR $\gamma$ t-deficient condition. Indeed, c-kit ${ }^{+} \mathrm{IL}_{-} \mathrm{CR}^{+} \mathrm{Lin}^{-} \mathrm{ROR} \gamma \mathrm{t}^{-}$ cells inside the CP and c-kit ${ }^{+} I L-7 R^{+} \mathrm{Lin}^{-} \mathrm{ROR} \gamma \mathrm{t}^{-}$and c-kit ${ }^{+} I L-7 \mathrm{R}^{+} \mathrm{Lin}^{-} \mathrm{ROR} \gamma \mathrm{t}^{\text {low }}$ cells outside the $\mathrm{CP}$ basically remain in the gut mucosa of ROR $\gamma \mathrm{t}$-deficient ROR $\gamma \mathrm{t}^{\text {EGFP/EGFP }}$ mice. Consistent with these non-Lti-like c-kit ${ }^{+} \mathrm{IL}_{-} \mathrm{ZR}^{+} \mathrm{Lin}^{-}$cells being gut $T$ cell progenitors, ROR $\gamma \mathrm{t}$-deficient mice develop the normal number of intestinal mucosal $\mathrm{T}$ cells. These results clearly reassert the intraintestinal differentiation of the body's largest peripheral T cell subpopulation.

\section{INTRODUCTION}

The hematopoietic system of the mouse small intestine includes diffusely distributed lymphomyeloid cells and $\mathrm{T}$ cells in the lamina propria (LP), numerous T cells in the epithelial cell layer (intraepithelial lymphocytes (IELs)), and organized gut-associated lymphoid tissues. Some of the gut-associated lymphoid tissues, such as mesenteric lymph nodes, Peyer's patches (PPs), and isolated lymphoid follicles ${ }^{1,2}$ harbor mature $\mathrm{T}$ and $\mathrm{B}$ cells. In contrast, recently identified cryptopatches $(\mathrm{CPs})^{3-5}$ are mostly constituted by $\mathrm{CD} 25^{+} \mathrm{c}-\mathrm{kit}^{+} \mathrm{IL}-7 \mathrm{R}^{+}$hematopoietic cells that do not express mature lineage markers $\left(\mathrm{Lin}^{-}\right)$. The $\mathrm{Lin}^{-} \mathrm{CP}$ populations seem a logical candidate to serve as a source of at least some subsets of mature intestinal $\mathrm{T}$ cells, but de facto, their relationship to mature intestinal lymphocytes has been a subject of much debate.

IELs may compose the largest population in the peripheral T cell pool ${ }^{6}$ and about half (type "a" IELs ${ }^{7}$ ) are conventional thymus-derived memory $\alpha \beta$ T cells expressing either CD4 or (more commonly) CD8 $\alpha \beta$. The remaining type " $\mathrm{b}$ " IELs ${ }^{7}$ have unique characteristics, frequently expressing either CD8 $\alpha \alpha$ homodimers and/or T cell receptor (TCR) $\gamma \delta$. Because they are clearly present in athymic nude (nu/nu) mice, it has been proposed that they differentiate outside the thymus within the gut mucosa. ${ }^{7-10}$ The identification of CP aggregates in the intestinal crypt LP as foci containing T cell progenitors provided evidence for a central site wherein IEL precursors, namely c-kit ${ }^{+} \mathrm{IL}_{-} 7 \mathrm{R}^{+} \mathrm{Lin}^{-} \mathrm{CP}$ cells, could initiate $\mathrm{T}$ cell differentiation. ${ }^{3-5}$ Indeed, the transfer of sorted c-kit ${ }^{+} \mathrm{Lin}^{-} \mathrm{CP}$ cells from 4-week-old nu/nu mice reconstituted the type b IEL compartment in sublethally irradiated severe combined immunodeficiency mice. ${ }^{4}$ Moreover, a broad spectrum of cellular ${ }^{4,5,9-14}$ and subcellular ${ }^{5,11,15,16}$ analyses support the notion that CPs harbor CD8 $\alpha \alpha^{+}$IEL precursors that develop extrathymically. Consistent with this, because TCR $\gamma$-V-J gene recombinations depend on interleukin-7 (IL-7)-mediated signaling, ${ }^{17}$ it is noteworthy that $\gamma \delta \mathrm{T}$ cells can be rescued in the gut (but not elsewhere) by the expression of IL-7 solely within the gut epithelium of IL- $7^{-1-}$ mice. ${ }^{10}$ These findings seemed to demonstrate the potential of local progenitors to differentiate into gut $\mathrm{T}$ cells.

Nonetheless, an extrathymic origin for type b IEL was challenged by Littman and co-workers based on observations in mice heterozygous for the insertion of an enhanced green fluorescence protein (EGFP) reporter into the gene encoding the retinoic acid-related orphan receptor- $\gamma \mathrm{t}(\mathrm{ROR} \gamma \mathrm{t}) .{ }^{18,19}$ Reflecting ROR $\gamma t$ expression, fetal lymphoid tissue inducer (Lti) cells and $\mathrm{CD} 4{ }^{+} \mathrm{CD} 8{ }^{+}$double-positive (DP) thymocytes

${ }^{1}$ Department of Microbiology and Immunology, Keio University School of Medicine, Shinjuku-ku, Tokyo, Japan. ${ }^{2}$ Department of Biochemistry and Integrative Medical Biology, Keio University School of Medicine, Shinjuku-ku, Tokyo, Japan. ${ }^{3}$ Department of Dermatology, Kyorin University School of Medicine, Mitaka, Tokyo, Japan. ${ }^{4}$ Department of Internal Medicine, Keio University School of Medicine, Shinjuku-ku, Tokyo, Japan. Correspondence: H Ishikawa (h-ishika@sc.itc.keio.ac.jp) 
in such mice are labeled with EGFP. ${ }^{19}$ ROR $\gamma \mathrm{t}$ (EGFP) was also reported to label all c-kit ${ }^{+} \mathrm{IL}_{-}-\mathrm{R}^{+} \mathrm{Lin}^{-}$cells (presumably $\mathrm{CP}$ cells) isolated from the gut wall. ${ }^{18}$ Importantly, ROR $\gamma$ t-deficient ROR $\gamma \mathrm{t}^{\mathrm{EGFP} / \mathrm{EGFP}}$ (EGFP/EGFP) mice were claimed to lack CP, to harbor reduced numbers of DP thymocytes, and to exhibit a drastic and specific reduction in all subsets of intestinal $\alpha \beta$ $\mathrm{T}$ cells including TCR $\alpha \beta^{+}$IEL ( $\alpha \beta$-IEL), although the generation of $\gamma \delta$-IEL was reportedly unchanged. ${ }^{18}$ Because type $b \alpha \beta$ $\mathrm{T}$ cells and DP thymocytes could subsequently be rescued by provision of a Bcl-xL transgene, ${ }^{18}$ whereas $\mathrm{CPs}$ could not, ${ }^{18}$ the origin of intestinal type $b \alpha \beta$ T cells was assigned to DP thymocytes, although the origin of $\gamma \delta$-IEL remained unresolved. At the same time, it was concluded that CPs did not nurture T cell progenitors but instead represent cell aggregates that eventually develop into isolated lymphoid follicles following intestinal luminal antigen-derived innate inflammatory signals transmit-

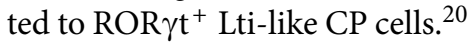

Given the overt contradiction of the work of Eberl and Littman ${ }^{18}$ with numerous seemingly compelling data sets, our major goals were to re-examine more thoroughly the phenotype of $\mathrm{Lin}^{-}$cells in $\mathrm{CP}$, and to re-evaluate the status of $\mathrm{CP}$ and type $\mathrm{b} \alpha \beta \mathrm{T}$ cells in the EGFP/EGFP mice used by Eberl and Littman and in athymic derivatives thereof. To characterize CP cells, we isolated them directly by micromanipulation. ${ }^{1,4,5,11}$ To investigate gut $\mathrm{T}$ cell subtypes, we carefully separated the $\mathrm{T}$ cells residing in the epithelium from those in the LP. Our results provide a profoundly enhanced view of the complexity of $\mathrm{CP}$, where the Lti-like component is shown to be a minor component, amid several other $\mathrm{Lin}^{-}$phenotypes, some of which lack ROR $\gamma \mathrm{t}$ expression. Such diverse $\mathrm{Lin}^{-}$cells, including those expressing ROR $\gamma \mathrm{t}$, are shown to express $\mathrm{T}$ cell markers, showing that ROR $\gamma t$ is not restricted to Lti-like cells, but, as in the thymus, is expressed in cells with $\mathrm{T}$ cell differentiation potential. Moreover, the development of $\mathrm{CP}$ is found to be reduced but not abrogated in the ROR $\gamma \mathrm{t}$-deficient condition, consistent with the finding that neither $\gamma \delta$-nor $\alpha \beta$-IEL is affected by the ROR $\gamma$ t deletion. Hence, the possibility that a substantial fraction of one of the body's largest $\mathrm{T}$ cell subsets develops locally is reasserted.

\section{RESULTS}

\section{C-kit ${ }^{+}$LL-7R+ Lin $^{-}$CP cells are heterogeneous}

The first goal was to re-examine the phenotype of $\mathrm{Lin}^{-}$cells in $\mathrm{CP}$, in response to the report that c-kit ${ }^{+} \mathrm{IL}_{-}-\mathrm{R}^{+} \mathrm{Lin}^{-}$cells isolated by collagenase digestion of the gut wall of ROR $\gamma \mathrm{t}^{\mathrm{EGFP} /+}$ $(\mathrm{EGFP} /+)$ mice were all EGFPhigh, reflective of their most likely being ROR $\gamma \mathrm{t}^{+}$Lti-like cells. Rather than crude collagenase digestion, we microdissected from the small intestines of nu/nu EGFP/ + or euthymic (nu/ + ) EGFP/ + mice very small tissue fragments $\left(\sim 0.13 \mathrm{~mm}^{3}\right)$, each containing one $\mathrm{CP},{ }^{1,4,5}$ and excluded surrounding mature cells using a $\mathrm{Lin}^{+}$cocktail composed of anti-CD3, anti-TCR $\alpha \beta$, anti-TCR $\gamma \delta$, anti-CD19, anti-Mac-1, anti-Gr-1, and anti-TER119 monoclonal antibodies (mAbs). This cocktail, unlike that of Eberl and Littman, did not contain anti-B220 and anti-CD11/c mAbs, as many type b IEL and immature gut $\mathrm{T}$ precursors express the corresponding markers. ${ }^{21}$ In contrast to earlier reports, ${ }^{18,19}$ EGFP staining clearly revealed three distinct populations of cells: $\mathrm{EGFP}^{-}, \mathrm{EGFP}^{\text {low, }}$ and EGFPhigh, respectively, in nu/nu EGFP/ + (Figure 1a and Supplementary Figure S1 online) and euthymic C57BL/6 (B6) $\mathrm{EGFP} /+$ mice $^{18}$ (Supplementary Figure S1 online). When Lin ${ }^{-}$ $\mathrm{CP}$ cell phenotypes were evaluated in more detail, $\sim 15 \%$ of cells were $\mathrm{CD}_{4} 4^{-} \mathrm{EGFP}^{-}$, most likely non-hemopoietic stromal cells that one would anticipate finding in $\mathrm{CP}$ isolates. Excluding these, the remaining $85 \%$ of cells were $\mathrm{CD} 25^{+}$, Thy-1 $1^{+/-}$, $\mathrm{IL}^{-7 \mathrm{R}^{+}}$, and/or c-kit ${ }^{+}$, but expressed different levels of EGFP (Figure 1a). The c-kit and IL-7R expression levels correlated to EGFP expression, i.e., were maximal in EGFPhigh cells and lower in $\mathrm{EGFP}^{-}$cells (Figure 1a and Supplementary Figure S1 online). In situ analysis of tissue sections from nu/nu EGFP/ + or $\mathrm{nu} /+\mathrm{EGFP} /+$ mice confirmed the existence of numerous c-kit ${ }^{+}$ $\mathrm{CP}$ cells that were $\mathrm{EGFP}^{-}$or EGFPlow (denoted by asterisks and circles in Figure 1b). We therefore conclude that CP cells are more heterogeneous than previously recognized, including many CP cells that do not express ROR $\gamma \mathrm{t}$. Moreover, because the Lin cocktail did not contain anti-CD4 mAb (an Lti cell marker), we could show CD4 ${ }^{+}$Lti cells to compose only one-quarter of c-kit ${ }^{+} \mathrm{Lin}^{-} \mathrm{EGFP}^{\text {high }}$ cells ( $15 \%$ of total c-kit ${ }^{+} \mathrm{IL}^{-7 \mathrm{R}^{+}} \mathrm{Lin}^{-}$ $\mathrm{CP}$ cells). Thus, the majority of CP cells comprise ROR $\gamma \mathrm{t}^{+}$and ROR $\gamma \mathrm{t}^{-}$cells that lack the "classical Lti cell" phenotype. We therefore examined other properties of intestinal ROR $\gamma \mathrm{t}^{+}$cells in more detail.

\section{c-kit ${ }^{+}$Lin $^{-}$ROR $\gamma \mathbf{t}^{+}$cells and $\mathrm{T}$ cell commitment}

The $\mathrm{T}$ lineage commitment of $\mathrm{c}-\mathrm{kit}^{+} \mathrm{Lin}^{-} \mathrm{CP}$ cells has been reported. ${ }^{5}$ Nonetheless, several independent studies are consistent with intestinal $\mathrm{T}$ cell differentiation proceeding from CP to the IEL compartment. ${ }^{9,11,15,22-24}$ Because IELs are more abundant than CP cells in the murine gut mucosa and hence tractable for phenotypic analysis, we used nu/nu EGFP/ + mice to investigate c-kit ${ }^{+} \mathrm{Lin}^{-}$IEL isolates in more detail. We found that the c-kit ${ }^{+} \mathrm{Lin}^{-}$cell fraction mirrored the $\mathrm{CP}$ compartment in harboring $\mathrm{EGFP}^{-}, \mathrm{EGFP}^{\text {low }}$, and EGFP ${ }^{\text {high }}$ cells (Figure 2). When purified and examined by semiquantitative reverse transcriptase-PCR (RT-PCR), each subset showed transcripts for $\mathrm{CD} 3 \varepsilon$, germline $\mathrm{J} \gamma 1-\mathrm{C} \gamma 1$ and/or $\mathrm{J} \gamma 2-\mathrm{C} \gamma 2$, and germline $C \beta$, reflective of $\mathrm{T}$ cell commitment ${ }^{5}$ (Figure 2), compared to the absence of these in $\mathrm{CD} 19^{+} \mathrm{B}$ cells. Thus, there is evidence of $\mathrm{T}$ cell commitment among intestinal

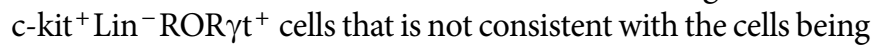
exclusively the adult counterparts of Lti cells. EGFP expression levels correlated well with the amount of ROR $\gamma \mathrm{t}$ mRNA, demonstrating that EGFP serves as a good indicator of ROR $\gamma \mathrm{t}$ (Figure 2b). This illustrated that ROR $\gamma t$ downregulation correlated with increased $\mathrm{T}$ cell differentiation status, with c-kit ${ }^{+} \mathrm{Lin}^{-} \mathrm{ROR} \gamma \mathrm{t}^{-}$cells

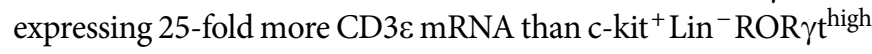
cells, and also expressing mRNAs for pre-T $\alpha$, terminal deoxynucleotidyl transferase (TdT), $\mathrm{V} \beta 8.1 / 2-\mathrm{C} \beta 1 / 2$, and $\mathrm{V} \gamma 7-\mathrm{C} \gamma 1$ gene rearrangements (Figure 2a). The data are consistent with other studies ${ }^{11,15,24,25}$ and suggest a hierarchy of $\mathrm{T}$ cell differentiation in the intestinal epithelium from a $\mathrm{c}^{-\mathrm{kit}^{+} \mathrm{Lin}^{-} \mathrm{ROR} \gamma \mathrm{t}^{\text {high }} \mathrm{T} \text { cell progenitor to more advanced }}$ $\mathrm{c}^{-} \mathrm{kit}^{+} \mathrm{Lin}^{-} \mathrm{ROR} \gamma \mathrm{t}^{-}$cells. 
a

Lin $^{-}$CP cells (nu/nu EGFP/+)
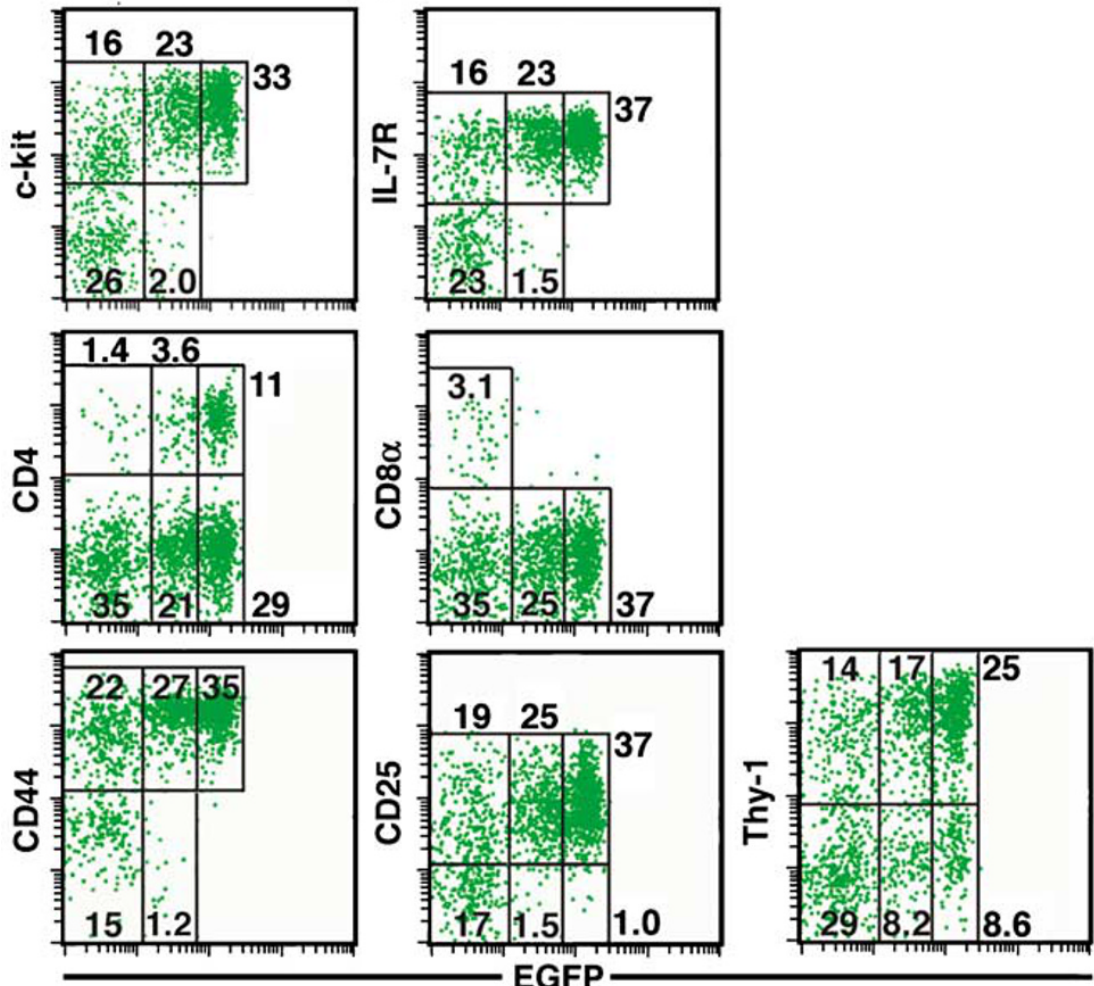

b

c-kit PE

EGFP
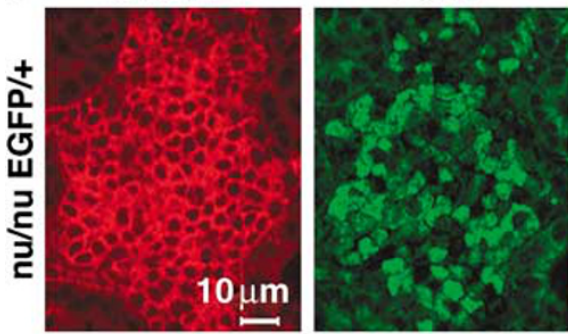

Merge
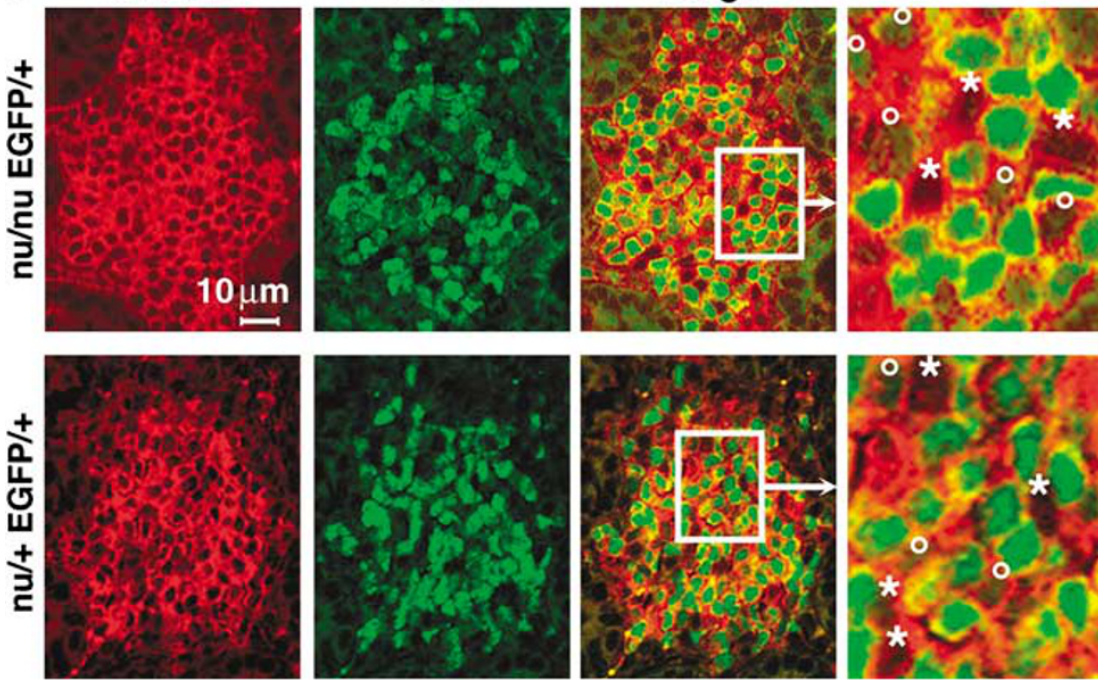

Figure 1 Flow cytometric and immunofluorescence analyses of CPs from nu/nu and nu/ + EGFP/+ mice. (a) Flow cytometric profiles of Lin- CP cells from nu/nu EGFP/+ mice. (b) In situ double immunofluorescence analysis of CPs from nu/nu EGFP/+ and nu/ + EGFP/+ mice. CPs were stained with anti-c-kit $\mathrm{mAb}(\mathrm{PE})$. Two rectangular areas indicated in the merge panels are magnified. Open circle $(O)$ indicates $\mathrm{c}-\mathrm{kit}^{+} \mathrm{EGFP} \mathrm{P}^{\mathrm{low}} \mathrm{CP}$ cells and asterisk $\left(^{\star}\right)$ indicates c-kit ${ }^{+}$EGFP- CP cells (right two panels). CP, cryptopatch; EGFP, enhanced green fluorescence protein; mAb, monoclonal antibody; PE, phycoerythrin.

\section{ROR $\gamma$ t deletion and CP}

Reflecting ROR $\gamma$ t deficiency, it was reported that EGFP/EGFP mice lack lymph nodes (LNs) ${ }^{19}$ and gut CPs. ${ }^{18}$ To re-evaluate this, the intestinal lengths of nu/ + EGFP/ + and nu/ + EGFP/EGFP mice and four nu/nu EGFP/ + and five nu/nu EGFP/EGFP mice were screened according to published methods. ${ }^{3} \mathrm{CPs}$, defined as clusters of Thy- $1^{+} \mathrm{c}-\mathrm{kit}{ }^{+} \mathrm{IL}-7 \mathrm{R}^{+}$cells surrounded by $\mathrm{CD} 11 \mathrm{c}^{+}$cells, were readily detectable in the gut mucosa of both Ly5.1 $1^{+}$B6 (wild-type) and nu/nu EGFP/ + mice, and in the gut mucosa of nu/nu EGFP/EGFP mice (Figure 3a), even though the latter did not develop LN. As in wild-type mice, CPs from EGFP/EGFP mice were filled with Thy- $1^{+}$cells, 
a
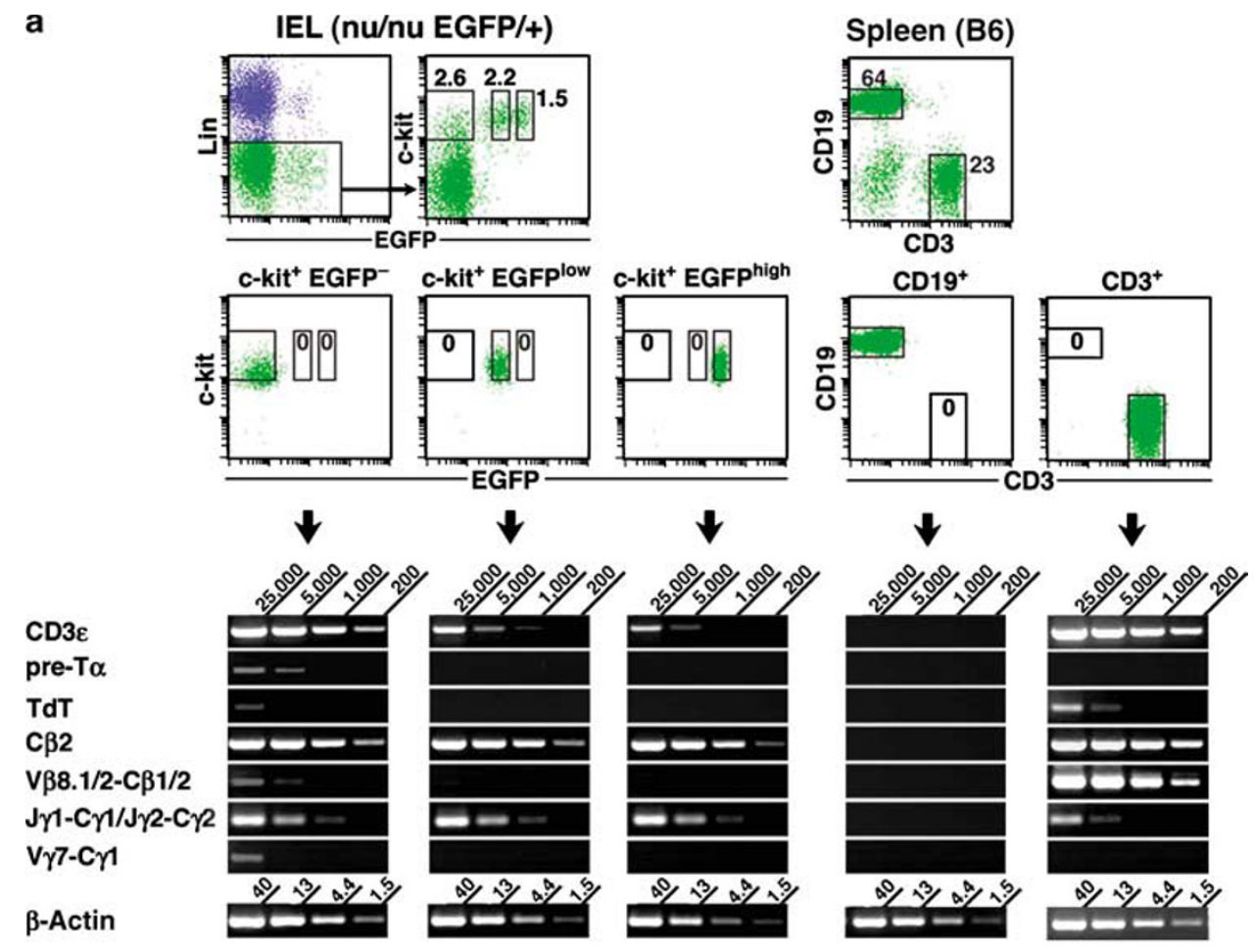

b

IEL (nu/nu EGFP/+)
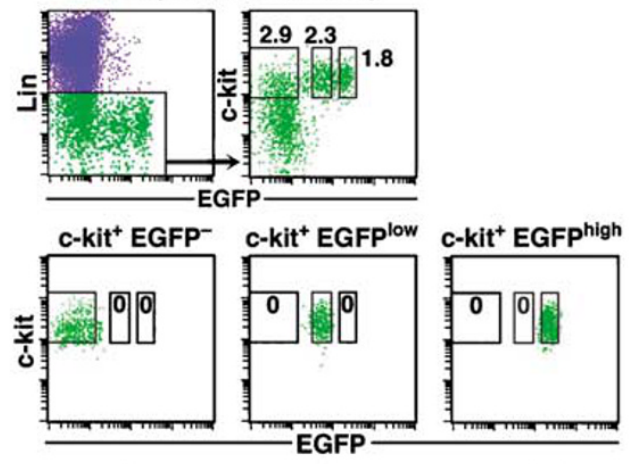

RORYt

EGFP

B-Actin

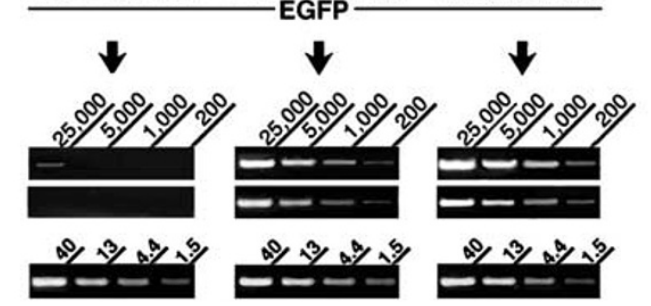

Figure 2 Flow cytometric profiles of IEL before and after purification by FACSaria and semiquantitative RT-PCR analysis of the purified cells. (a) CD3 $\varepsilon$, pre-T $\alpha$, TdT, TCR-C $\beta 2$, rearranged TCR-V $\beta 8.1 / 2-C \beta 1 / 2$, germline TCR $\gamma$, and rearranged TCR-V $\gamma 7-C \gamma 1$ mRNA levels in sorted c-kit ${ }^{+}$Lin-EGFP- $^{-}$, c-kit ${ }^{+}$Lin-EGFPlow, and c-kit ${ }^{+}{ }^{-}$in-EGFPhigh IELs from nu/nu EGFP/+ mice and splenic B $\left(\right.$CD19+ ${ }^{+}$) and T $\left(C D 3^{+}\right)$cells from B6 mice. (b) ROR $\gamma t$ and EGFP mRNA levels in sorted c-kit ${ }^{+}$Lin $^{-}$EGFP- ${ }^{-}$c-kit ${ }^{+}$Lin ${ }^{-}$EGFPlow, and c-kit ${ }^{+}$Lin-EGFPhigh IELs from nu/nu EGFP/+ mice. EGFP, enhanced green fluorescence protein; IEL, intraepithelial lymphocyte; ROR $\gamma \mathrm{t}$, retinoic acid-related orphan receptor- $\gamma \mathrm{t}$; RT, reverse transcriptase; TCR, T-cell receptor; TdT, terminal deoxynucleotidyl transferase.

circumscribed by CD11 $\mathrm{c}^{+}$cells, albeit their c-kit and IL-7R expression was reduced. They occurred in approximately sevenfold reduced numbers (53 per nu/nu EGFP/EGFP mouse vs. 379 per nu/nu EGFP/ + mouse), and although many were small, some were normal in size. We also detected phenotypically the same CP cells and a decreased number of CPs in the gut mucosa of nu/ + EGFP/EGFP mice (data not shown) as those detected in the gut mucosa of nu/nu EGFP/EGFP mice (Figure 3a). These results show that at least some of the c-kit ${ }^{\text {low } I L-7 R^{\text {low }}}$ cells usually present in normal CPs (Figures 1 and 2 and Supplementary Figure S1 online) basically remain in ROR $\gamma \mathrm{t}$-deficient mice, albeit their numbers may be reduced. 


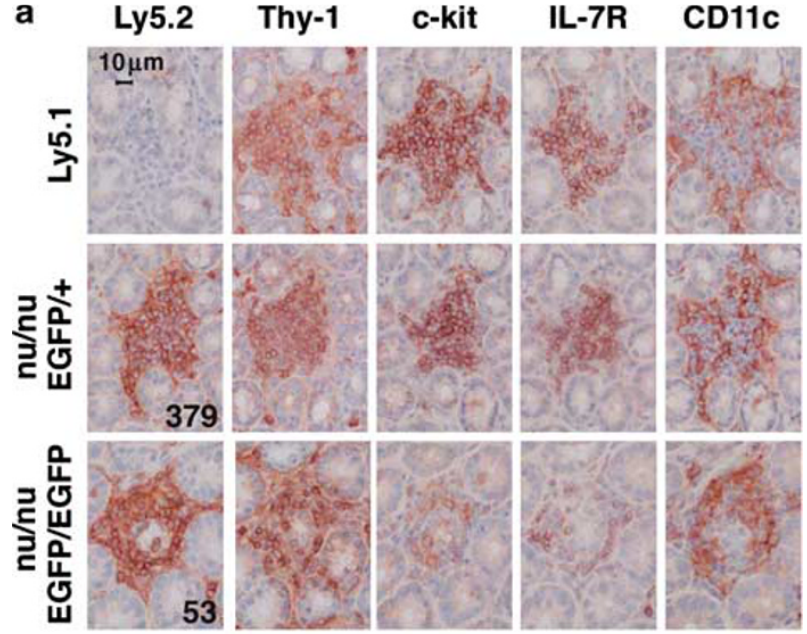

b
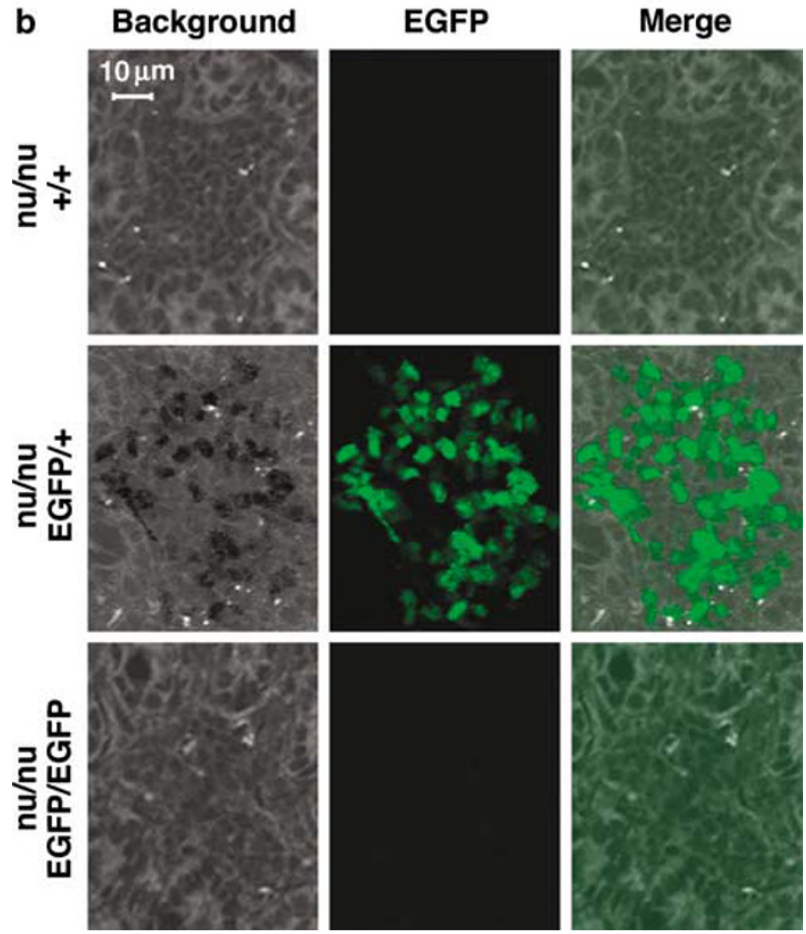

Figure 3 Immunohistochemical and immunofluorescence characterizations of CPs in the small intestines from nu/nu EGFP/+ and nu/nu EGFP/EGFP mice. (a) Representative immunohistochemical visualizations of Ly5.2 $2^{+}$, Thy- $1^{+}, \mathrm{C}^{-k i t^{+}}, \mathrm{IL}-7 \mathrm{R}^{+}$, and CD11C ${ }^{+}$ lymphocytes in CPs from B6 Ly5.1, nu/nu EGFP/+, and nu/nu EGFP/EGFP mice. The enumeration of CPs per small intestine of nu/nu EGFP/+ mice $(n=4)$ and nu/nu EGFP/EGFP mice $(n=5)$ was performed according to the method described elsewhere, ${ }^{3,11}$ and average numbers of CPs were indicated. Note that Ly5.2 $2^{+}$Thy- $1^{+}$c-kit ${ }^{-/ l o w} / L-7 R^{-/ l o w}$ cells reside in CP from nu/nu EGFP/EGFP mice. (b) Representative immunofluorescence visualizations of EGFP-bearing cells in CPs of $\mathrm{nu} / \mathrm{nu}+/+(n=2)$, nu/nu EGFP/+ $(n=3)$, and nu/nu EGFP/EGFP $(n=6)$ mice. Note that CPs from nu/nu $+/+$ and nu/nu EGFP/EGFP mice lack EGFP ${ }^{+}$cells. CP, cryptopatch; EGFP, enhanced green fluorescence protein.

In summary, ROR $\gamma \mathrm{t}^{+}$cells favor the establishment of $\mathrm{CP}$ but are clearly not essential, in striking contrast to the situation for LN. Immunofluorescence study demonstrated that ROR $\gamma \mathrm{t}-$ bearing $\mathrm{EGFP}^{+}$cells congregated in the $\mathrm{CP}$ of nu/nu EGFP $/+$ mice but not in the CP of nu/nu ROR $\gamma \mathrm{t}^{+/+}(+/+)$and ROR $\gamma \mathrm{t}$ deficient nu/nu EGFP/EGFP (Figure 3b) and nu/ + EGFP/EGFP mice (data not shown). In contrast, $\mathrm{EGFP}^{+}$thymocytes were present in nu/ + EGFP/EGFP mice ${ }^{19}$ (Supplementary Figure S2 online). It should also be noted that EGFP/EGFP mice harbor

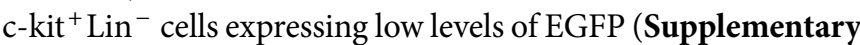
Figure S3 online) as well as c-kit ${ }^{+} \mathrm{Lin}^{-} \mathrm{EGFP}^{-}$cells that are dispersed throughout the LP (data not shown), suggesting that precursor cells in these mice may also be located outside the $\mathrm{CP}$, perhaps reflecting the reduced formation of $\mathrm{CP}$.

\section{c-kit ${ }^{+}$and $\mathbf{R O R} \gamma \mathbf{t}^{+}$cells in ontogeny}

CPs are formed between 7 and 14 days after birth, ${ }^{1,3}$ outside the conventional (fetal) window for Lti cells. To examine where ${\mathrm{c}-\mathrm{kit}^{+}}^{+}$and ROR $\gamma \mathrm{t}^{+}$cells localize at this time, small intestines of day $10 \mathrm{nu} / \mathrm{nu} \mathrm{EGFP} /+$ and nu/ + EGFP/ + mice were examined. c-kit ${ }^{+}$cells were detected, both dispersed (Figure 4a,c) and congregated within the nascent 15-20 developing small CPs (Figure $4 \mathbf{b}, \mathbf{d}$ ), and similarly dispersed c-kit ${ }^{+}$cells were detected in ROR $\gamma \mathrm{t}$-deficient EGFP/EGFP mice (data not shown). As with the analyses of isolated Lin $^{-} \mathrm{CP}$ cells in adult mice (Figure 1a), the ${\mathrm{c}-\mathrm{kit}^{+}}^{+}$cells in each location showed a spectrum of EGFP expression. Hence, from early time points, CPs do not merely comprise $\mathrm{ROR} \gamma \mathrm{t}^{+}$Lti-like cells but rather contain a mixture of ROR $\gamma \mathrm{t}^{+}$and ROR $\gamma \mathrm{t}^{-}$cells. However, in the crypt LP outside the $\mathrm{CP}$ in adult nu/ + EGFP/ + mice, c-kit ${ }^{+} \mathrm{EGFP}^{-}$cells predominated and it was difficult to discern DP c-kit ${ }^{+} \mathrm{EGFP}^{+}$ cells (Figure 4e), perhaps representing advanced $\mathrm{T}$ cell progenitors en route to the epithelium (see above). In summary, the diffusion in perinatal mice of $\mathrm{ROR} \gamma \mathrm{t}^{+}$progenitors, compared to their clustering into $\mathrm{CP}$ in adult mice, is consistent with a model by which $\mathrm{ROR} \gamma \mathrm{t}^{+}$progenitors contribute to $\mathrm{CP}$ organogenesis where they interact with $\mathrm{ROR} \gamma \mathrm{t}^{-}$cells to provide the postnatal gut with a condensed site for $\mathrm{T}$ cell differentiation. Of note, 10-day-old murine gut sections also revealed dispersed

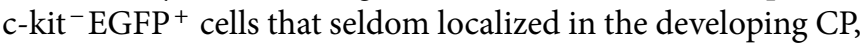
and that were rarely detected in and around the $\mathrm{CP}$ of adult mice (Figure 4e,f). Although these cells require further study, they may reflect the early appearance of ROR $\gamma \mathrm{t}^{+}$Th17 cells that in adults constitutively localize to the LP. ${ }^{26}$

\section{The impact of ROR $\gamma$ t deletion on gut Tymphocytes}

Eberl and Littman ${ }^{18}$ initially reported that mature $\mathrm{T}$ cells in the gut fail to express ROR $\gamma \mathrm{t}$ at steady state and hence are not labeled in EGFP/ + mice. Because they also found that intestinal $\alpha \beta \mathrm{T}$ cells are drastically reduced in EGFP/EGFP mice, they assigned the cells' origin to ROR $\gamma \mathrm{t}$-dependent DP thymocytes. ${ }^{18}$ A subsequent study by the same group ${ }^{26}$ using a different isolation procedure for mucosal $\mathrm{T}$ cells then revealed the presence of a small fraction of $\alpha \beta$ and $\gamma \delta$ T cells expressing EGFP, a finding that we confirmed (Supplementary Figure $\mathbf{S} 3$ online). Of note, we also corroborated that a fraction of the precursor cells expressing lower EGFP levels survive the ROR $\gamma t$ deletion in the gut mucosa of both nu/ + and nu/nu mice (Supplementary Figure S3 online). However, in stark contrast to Eberl and 


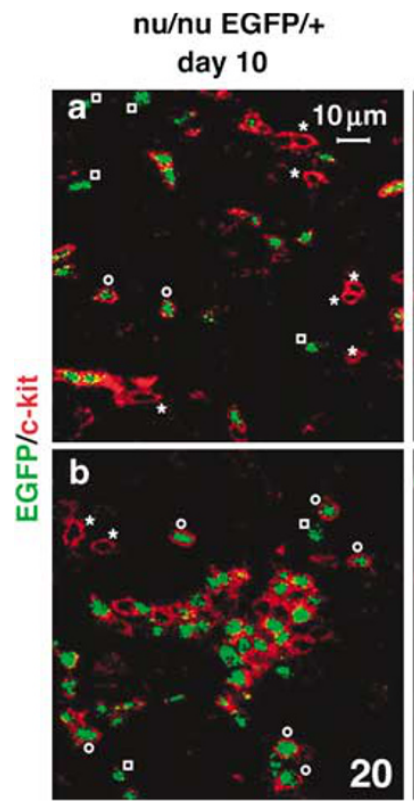

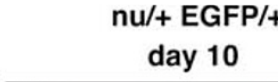
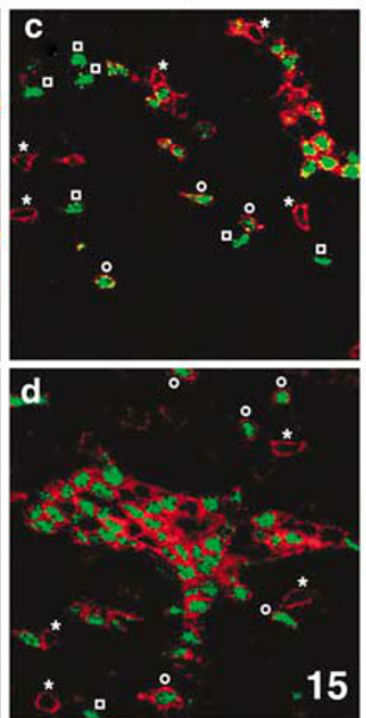

$\mathrm{nu} /+\mathrm{EGFP} /+$

day 85

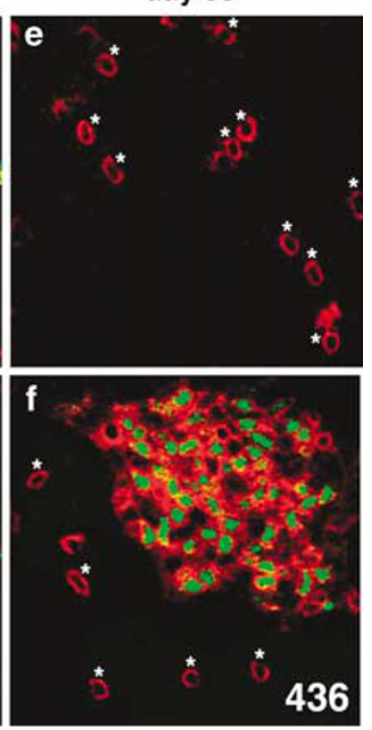

Figure 4 Organogenesis of CPs at day 10 of postnatal life in nu/nu EGFP/+ and nu/ + EGFP/+ mice. c-kit ${ }^{+}$EGFP- cells (red, ${ }^{*}$ ), c-kit ${ }^{+}$EGFP ${ }^{+}$cells (red and green, $O$ ), and c-kit ${ }^{-} E G F P+$ cells (green, $\square$ ) are dispersed and present along the length of the small intestinal crypt LP, including the mucosa adjacent to the developing small CPs in (a and $\mathbf{b})$ nu/nu EGFP/ + and (c and $\mathbf{d})$ nu/ + EGFP/+ mice. (e and $\mathbf{f})$ In contrast, only c-kit ${ }^{+}$EGFP- cells $\left(\right.$ red, $\left.{ }^{*}\right)$ can be detected outside CPs in the small intestinal crypt LP of adult nu/ + EGFP/+ mice. Average numbers of small CPs per intestine at the 10th postnatal day $(n=4-5)$ and normal size CPs at the 85th postnatal day $(n=3)$ were indicated. CP, cryptopatch; EGFP, enhanced green fluorescence protein; LP, lamina propria.

Littman, ${ }^{18}$ we found no evidence for any dependence of any gut $\mathrm{T}$ cell populations on ROR $\gamma \mathrm{t}$ : in both $\mathrm{B} 6$ mice and $\mathrm{nu} /+$ mice carrying the mixed $\mathrm{B} 6$ and $\mathrm{B} / \mathrm{c}$ backgrounds, ROR $\gamma \mathrm{t}$ deficiency superimposed on the different genetic backgrounds affected neither the absolute numbers of $\alpha \beta$ and $\gamma \delta$ T cells nor the relative enrichment of type b CD $8 \alpha \alpha^{+} \alpha \beta$-IEL compared to other subsets of $\alpha \beta$-IEL (Figure 5a,b). TCR V $\gamma$ gene usage by $\gamma \delta$-IEL was also unaffected (Figure 5c). Furthermore, in both athymic and euthymic conditions, the ROR $\gamma \mathrm{t}$ mutation affected neither the composition nor the absolute numbers of $\alpha \beta$ and $\gamma \delta$ T cells either in the IEL (Figure 6a) or the LP (Figure 6b) compartments.

\section{DISCUSSION}

The CD $8 \alpha \alpha^{+}$IELs that line the gut mucosa are highly abundant $\mathrm{T}$ cells with unique characteristics. They appear to be agonistselected with a unique LFA- $1^{-} \mathrm{CD} 5^{-}$Thy- $1^{+/-}$phenotype, together with a $\mathrm{CD} 3$ complex different from that of conventional type a thymus-derived IEL. ${ }^{7}$ Their presence in $\mathrm{nu} / \mathrm{nu}$ mice indicates that they can be generated outside the thymus, and it is one criterion for terming them unconventional type $b$ IEL. ${ }^{7}$ We do not contend that extrathymic T cell differentiation is as efficient as it is in the thymus, consistent with which neither we nor others have detected an abundance or complexity of extrathymic $\mathrm{T}$ cell precursors in the gut of nu/nu mice that would compare with that of thymic precursors. ${ }^{27}$ Nonetheless, the identification of $\mathrm{CP}$ harboring cells with a $\mathrm{CD} 44^{+} \mathrm{CD} 25^{+/-}$ c-kit ${ }^{+} \mathrm{IL}-7 \mathrm{R}^{+} \mathrm{Lin}^{-}$phenotype, ${ }^{5}$ and our demonstration that transfer of these CP cells to sublethally irradiated severe combined immunodeficiency mice would selectively reconstitute $\alpha \beta$ - and $\gamma \delta$-IEL, ${ }^{4}$ showed that CP can be an initial source of local type b IEL precursors. ${ }^{4,5,7,10-16}$ Moreover, it was recently shown that $\mathrm{CD}^{-}{ }^{-} \mathrm{CD} 8^{-} \mathrm{TCR}^{-}$thymocyte precursors may leave the thymus before TCR gene rearrangement and colonize the gut $\mathrm{CPs}$, which are then able to reconstitute a full "euthymic" type b compartment, i.e., containing as many $\alpha \beta \mathrm{T}$ cells as those found in normal mice. These data seemingly established a fundamental role of local precursors in the generation of type b IEL, restricting the role of the thymus to improving $\alpha \beta$ T cell commitment and thus promoting local differentiation. ${ }^{27}$ This notion was further supported by an extensive definition of lineage relationships of $\mathrm{Lin}^{-}$cells located in the CP and the epithelium. In particular, the expression frequency of $\mathrm{T}$ cell lineage molecular markers, the sequence of TCR rearrangements, and the impact of different mutations affecting $\mathrm{T}$ cell differentiation in local $\mathrm{Lin}^{-}$gut populations collectively delineated a differentiation process initiating in the $\mathrm{CP}$ and ending in the epithelium. ${ }^{4,15,25,28}$ The results presented in this study take further the issue of extrathymic $\mathrm{T}$ cell differentiation and specifically question conclusions drawn from an earlier study of ROR $\gamma \mathrm{t}$-EGFP mice. ${ }^{18}$ Collectively, the results reassert the candidacy of local progenitors as a prime source of intestinal mucosal T cells.

Specifically, we have shown that CPs are not simply aggregates of Lti-like cells but are composed of heterogeneous populations

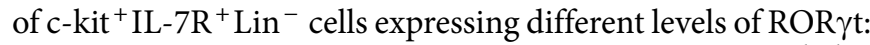
less than $15 \%$ displayed a classical c-kit ${ }^{+} \mathrm{IL}_{-}-7 \mathrm{R}^{+} \mathrm{Lin}^{-} \mathrm{EGFP}^{\text {high }} \mathrm{C}$ $\mathrm{D}^{+}{ }^{+}$Lti phenotype. ${ }^{19,29}$ It is quite likely that some c-kit ${ }^{+} \mathrm{ROR} \gamma \mathrm{t}^{+}$ $\mathrm{CP}$ cells perform Lti cell-like function, as we find that they 

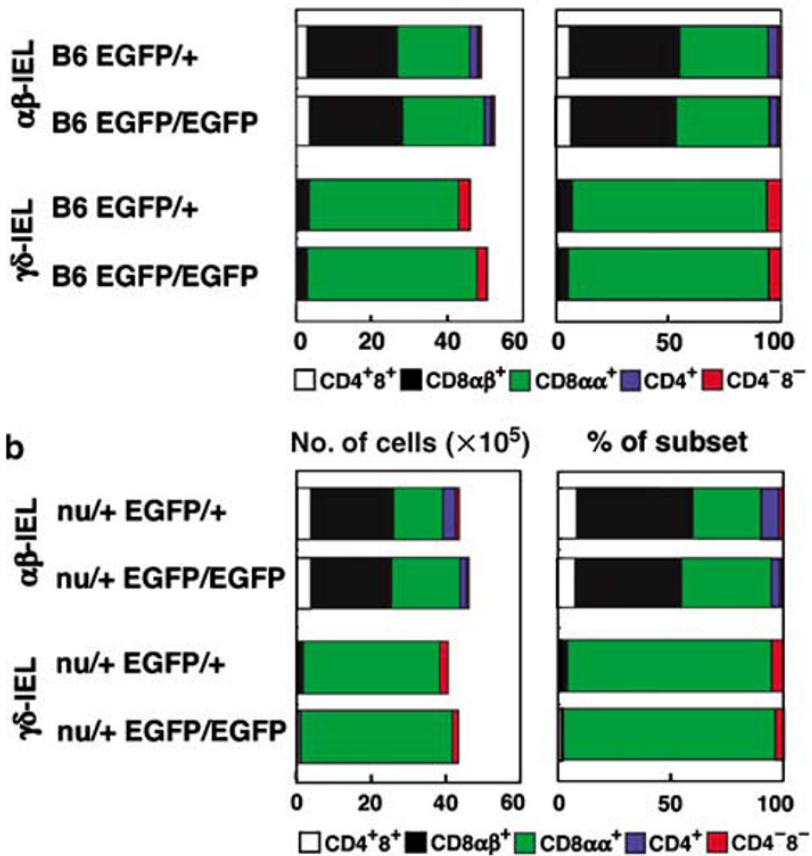

C

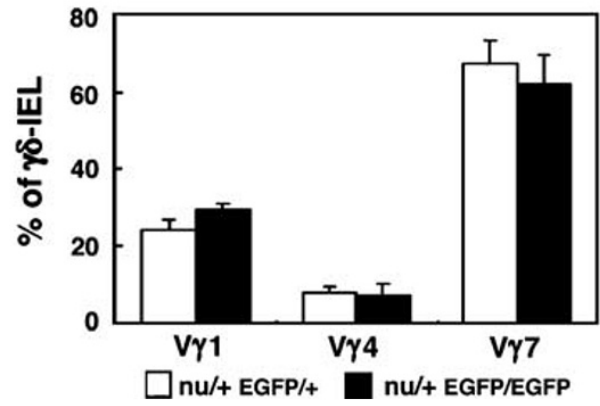

Figure 5 Flow cytometric analysis of $\alpha \beta$ - and $\gamma \delta$-IEL subsets in B6 EGFP/+, B6 EGFP/EGFP, nu/+ EGFP/+, and nu/+ EGFP/EGFP mice. (a) Absolute numbers and composition (\%) of double-positive $\left(\mathrm{CD} 4^{+} 8^{+}\right)$, single-positive $\left(\mathrm{CD} 8 \alpha \beta^{+}, \mathrm{CD} 8 \alpha \alpha^{+}\right.$, or $\left.\mathrm{CD} 4^{+}\right)$, and double-negative $\left(\mathrm{CD} 4^{-} 8^{-}\right)$subsets in $\alpha \beta$ - and $\gamma \delta$-IEL populations in B6 EGFP/+ and B6 EGFP/EGFP mice were calculated on the basis of total numbers of $\alpha \beta$ - and $\gamma \delta$-IELs, respectively. Data shown are the mean values from four B6 EGFP/+ and five B6 EGFP/EGFP mice, respectively. (b) Absolute numbers and composition (\%) of double-positive $\left(\mathrm{CD} 4^{+} 8^{+}\right)$, single-positive $\left(\mathrm{CD} 8 \alpha \beta^{+}, \mathrm{CD} 8 \alpha \alpha^{+}\right.$, or $\left.\mathrm{CD} 4^{+}\right)$, and double-negative $\left(C D 4^{-} 8^{-}\right)$subsets in $\alpha \beta$ - and $\gamma \delta$-IEL populations in nu/ + EGFP/+ and $\mathrm{nu} /+$ EGFP/EGFP mice were calculated on the basis of total numbers of $\alpha \beta$ - and $\gamma \delta$-IELs, respectively. Data shown are the mean values from five $\mathrm{nu} /+\mathrm{EGFP} /+$ and nu/ + EGFP/EGFP mice. (c) $V \gamma$ gene segments used by $\gamma \delta$-IELs from nu/ + EGFP/+ and nu/ + EGFP/EGFP mice. The results are the mean \pm s.e. of data obtained from four nu/ + EGFP/+ and nu/+ EGFP/EGFP mice. EGFP, enhanced green fluorescence protein; IEL, intraepithelial lymphocyte.

aggregate with c-kit ${ }^{+} \mathrm{ROR} \gamma \mathrm{t}^{-} \mathrm{CP}$ cells in $\mathrm{CP}$ biogenesis during the perinatal period and the $\mathrm{CP}$ numbers are clearly reduced in EGFP/EGFP mice. However, we note two $\mathrm{Lin}^{-}$cells expressing ROR $\gamma t^{\text {tow }}$ and ROR $\gamma \mathrm{t}^{\text {high }}$ that also show markers of T cell commitment. These results diversify the cell types that may express ROR $\gamma \mathrm{t}$. In fact, the concept that peripheral ROR $\gamma t$ expression
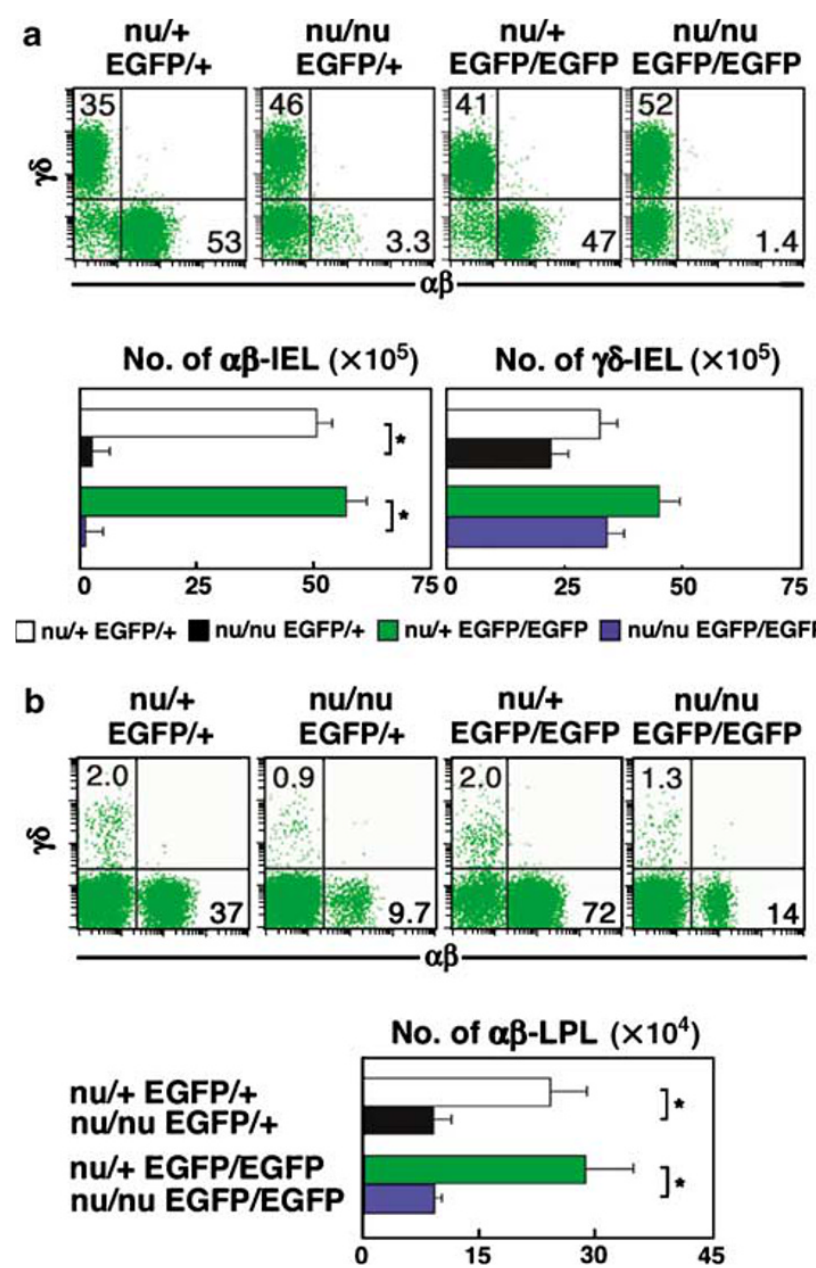

Figure 6 Flow cytometric analysis of $\alpha \beta$ and $\gamma \delta$ T cells that settle in the $\mathrm{LP}$ and intestinal epithelial cell (IEC) compartments of nu/+ EGFP/+, nu/+ EGFP/EGFP, nu/nu EGFP/+, and nu/nu EGFP/EGFP mice. (a) The composition of $\alpha \beta$ - and $\gamma \delta$-IELs and average numbers of $\alpha \beta$ - and $\gamma \delta$-IELs from nu/+ EGFP/+ ( $n=9$, white bar), nu/nu EGFP/+ $(n=7$, black bar), nu/+ EGFP/EGFP ( $n=6$, green bar), and nu/nu EGFP/EGFP ( $n=7$, blue bar) mice are shown. ${ }^{*} P<0.001$. (b) The composition of $\alpha \beta$ and $\gamma \delta$ T cells in LPL and average numbers of $\alpha \beta$ T cells from nu/ $\mathrm{EGFP} /+(n=6$, white bar), nu/nu EGFP/ + ( $n=5$, black bar), nu/ + EGFP/EGFP ( $n=4$, green bar), and nu/nu EGFP/EGFP ( $n=4$, blue bar) mice are shown. ${ }^{*} P<0.001$. EGFP, enhanced green fluorescence protein; IEL, intraepithelial lymphocyte; LP, lamina propria; LPL, lamina proprial lymphocyte.

may also be a feature of $\mathrm{T}$ cell progenitors would seem to parallel the expression of ROR $\gamma t$ by triple negative thymocytes and its upregulation after TCR $\beta$ selection. ${ }^{30}$ Since then, ROR $\gamma \mathrm{t}^{+} \mathrm{DP}$ thymocytes have also been implicated in multiple aspects of $\mathrm{T}$ cell differentiation. Although ROR $\gamma \mathrm{t}^{+} \mathrm{DP}$ thymocytes may themselves be progenitors of mature $\mathrm{T}$ cells, they can also transcondition the differentiation of ROR $\gamma \mathrm{t}^{-} \mathrm{T}$ cell progenitors. ${ }^{31} \mathrm{It}$ is thus possible that extrathymic $\mathrm{T}$ cell properties are likewise influenced in trans by the presence of ROR $\gamma \mathrm{t}^{+}$cells.

Our results also show that $\mathrm{CP}$ organogenesis follows different rules from that of LN and PP. First, CP formation is initiated in the postnatal period and, moreover, $\mathrm{CP}$ can be generated throughout life. Indeed, CP formation throughout adulthood can be promoted by the injection of $\mathrm{T}$ cell-depleted wild-type 
bone marrow cells into athymic cytokine receptor $\gamma$-chain mutant $\left(\gamma_{c}^{-1-}\right)$ mice 5 or by neonatal RAG-2-/- thymus transplantation into thymectomized double-mutant RAG-2-1- $\gamma_{c}{ }^{-1-}$ mice $^{27}$ that ordinarily lack CP.,11,27 By comparison, $\mathrm{LN}$ and $\mathrm{PP}$ generation is restricted to the fetal period. Second, $\mathrm{CP}$ generation is not abrogated by ROR $\gamma$ t deletion, as in EGFP/EGFP mice the number of CPs is reduced by less than sevenfold and a substantial number of CPs appear normal in size, asserting that $\mathrm{ROR} \gamma \mathrm{t}$ is not an absolute requirement for $\mathrm{CP}$ formation. Clear precedence for heterogeneity in lymphoid organogenesis exists in the nasopharyngeal-associated lymphoid tissue, which also differs markedly from PP and LN development ${ }^{32,33}$ in requiring the Id 2 gen ${ }^{32}$ and $\mathrm{CD} 3^{-} \mathrm{CD} 4{ }^{+} \mathrm{CD} 45^{+}$cells, ${ }^{32}$ but not the IL-7R $\alpha$ chain, ${ }^{32}$ the nuclear factor- $\kappa \mathrm{B}$-inducing kinase, ${ }^{32}$ and ROR $\gamma \mathrm{t} .{ }^{33}$ We reported previously that the organogenesis of $\mathrm{CP}$ is not dependent on IL-7 $\mathrm{R}^{11}$ or nuclear factor- $\mathrm{\kappa B}$-inducing kinase $^{3}$ signaling pathways, and we now report that it occurs even in the ROR $\gamma \mathrm{t}$-deficient condition, strongly suggesting that nasopharyngeal-associated lymphoid tissue and CP organogenesis pathways might follow the same rules. It was also reported that lymphotoxin-mutant $\left(\mathrm{LT}^{-/-}\right)$mice devoid of secondary lymphoid organs develop inducible bronchus-associated lymphoid tissue after lung infections. ${ }^{34}$

In contrast to previous data, we show that type b IELs are not affected by the ROR $\gamma$ t mutation. Again, our different results are likely explained by different methods employed to isolate the different cell types. The previous study cited crude collagenase isolates of the gut wall, ${ }^{18}$ which in our hands prevent accurate discrimination between LP and IEL populations and risk contamination by PP cells and also by epithelial cells that die easily after isolation, leading to the formation of large clumps that hinder population size and discrimination.

Finally, it remains to be addressed why the reduction in the number of CPs we found in ROR $\gamma \mathrm{t}$-deficient mice does not affect IEL generation. We suggest that if local precursors are yet present, their formal congregation into CP may not be fundamental for the generation of IEL. Indeed, $\mathrm{LT}^{-1-}$ mice that lack $\mathrm{CP}^{35}$ have abundant $\mathrm{c}-\mathrm{kit}^{+} \mathrm{Lin}^{-}$progenitors scattered throughout the LP and generate an abundant contingent of type $\mathrm{b}$ $\mathrm{T}$ cells. Similarly, we also identified numerous c-kit ${ }^{+} \mathrm{ROR} \gamma \mathrm{t}^{-}$ and $\mathrm{c}-\mathrm{kit}^{+} \mathrm{ROR} \gamma \mathrm{t}^{\text {low }}$ cells in the crypt LP outside CP in the ROR $\gamma \mathrm{t}$-deficient mice. As T cell-committed precursors have the $\mathrm{c}^{\mathrm{kit}}{ }^{+} \mathrm{ROR} \gamma \mathrm{t}^{- \text {low }}$ phenotype, it is possible that a sizable fraction of the gut $\mathrm{T}$ cell precursors basically remain in the ROR $\gamma \mathrm{t}-$ deficient mice. Alternatively or additionally, a reduction of precursor numbers may be compensated by subsequent homeostatic expansion.

\section{METHODS}

Mice. C57BL/6J Jcl (B6) and athymic BALB/cA Jcl (nu/nu B/c) mice were purchased from CLEA Japan (Tokyo, Japan). C57BL/6J-Ly5.1 (B6 Ly5.1) mice were described elsewhere. ${ }^{36} \mathrm{~B} 6$ ROR $\gamma \mathrm{t}{ }^{\mathrm{EGFP} / \mathrm{EGFP}}$ (B6 EGFP/ EGFP) mice ${ }^{18}$ were a gift from D. Littman (Molecular Pathogenesis Program and Howard Hughes Medical Institute, Skirball Institute of Biomolecular Medicine, New York University School of Medicine, New York, NY) and B6 EGFP/ + mice were obtained by crossing these B6
EGFP/EGFP mice with wild-type B6 mice. The B6 EGFP/EGFP female mice were crossed with $\mathrm{nu} / \mathrm{nu} \mathrm{B/c}$ male mice, and their heterozygous $\mathrm{nu} /+\mathrm{EGFP} /+$ progeny were backcrossed to $\mathrm{nu} / \mathrm{nu} \mathrm{B} / \mathrm{c}$ mice to obtain $\mathrm{nu} / \mathrm{nu} \mathrm{EGFP} /+$ and nu/ + EGFP/ + mice. By crossing these nu/ + $\mathrm{EGFP} /+$ female and nu/nu EGFP/ + male mice, we generated nu/ + $\mathrm{EGFP} /+, \mathrm{nu} /+\mathrm{EGFP} / \mathrm{EGFP}, \mathrm{nu} / \mathrm{nu} \mathrm{EGFP} /+$, and nu/nu EGFP/EGFP littermate mice. Mice were typed by PCR analysis of tail DNA with a set of primers for the wild-type ROR $\gamma$ t gene described elsewhere ${ }^{19}$ and for the mutant ROR $\gamma \mathrm{t}^{\mathrm{EGFP}}$ gene: 5'-GCGAGGGCGATGCCACCTACGG CA-3' and 5' -GGGTGTTCTGCTGGTAGTGGTCGG-3' (450 bp PCR fragment). The absence of the LN and PP in EGFP/EGFP mice lacking ROR $\gamma t$ was checked at necropsy. These mice were maintained under specific pathogen-free conditions, and all animal procedures described in this study were performed in accordance with the guidelines for animal experiments of Keio University School of Medicine.

Antibodies. The following mAbs, described previously, ${ }^{1,3-5,11,14}$ were used. For immunohistochemical and immunofluorescence staining, purified anti-c-kit (ACK-2), anti-IL-7R (A7R34), and anti-CD11/c (N418) mAbs and biotinylated anti-Ly5.2 (104; BD Pharmingen, San Diego, CA) and anti-Thy-1 (30-H12; BD Pharmingen) mAbs were used. For flow cytometric analysis, fluorescein isothiocyanate-conjugated anti-CD3 (145-2C11; BD Pharmingen), anti-CD8 $\alpha$ (53-6.7; BD Pharmingen), anti- $\mathrm{V} \gamma 1$ (2.11; gift from $\mathrm{S}$. Tonegawa, Center for Learning and Memory, MIT, Cambridge, MA), anti-V $\gamma 4$ (UC3-10A6), and anti-V $\gamma 7$ (GL-1; gift from L. Lefrancois, Department of Medicine, Division of Immunology, University of Connecticut Health Center, Farmington, CT) mAbs were used. Biotinylated anti-c-kit (ACK-4), anti-IL-7R $\alpha$ (A7R34; eBioscience, San Diego, CA), anti-TCR $\alpha \beta$ (H57-597; BD Pharmingen), anti-TCR $\gamma \delta$ (GL3; BD Pharmingen), anti-CD4 (GK1.5; BD Pharmingen), anti$\mathrm{CD} 8 \alpha$ (53-6.7; BD Pharmingen), anti-CD8 $\beta$ (53-5.8; BD Pharmingen), anti-CD44 (1M7; BD Pharmingen), anti-CD25 (7D4; BD Pharmingen), and anti-Thy-1 (30-H12; BD Pharmingen) mAbs were used. Phycoerythrin (PE)-conjugated anti-c-kit (ACK-2; eBioscience), anti-TCR $\alpha \beta$ (H57-597; BD Pharmingen), anti-TCR $\gamma \delta$ (GL3; BD Pharmingen), anti-CD3 (145-2C11; BD Pharmingen), anti-CD19 (1D3; BD Pharmingen), anti-Mac-1 (M1/70; BD Pharmingen), antiGr-1 (RB6-8C5; BD Pharmingen), and anti-TER119 (TER119; BD Pharmingen) $\mathrm{mAbs}$ were also used.

Immunohistochemical analysis. Immunohistochemical staining was carried out according to the method described elsewhere. ${ }^{1,3}$ In brief, a longitudinally opened small intestine, $\sim 10 \mathrm{~mm}$ in length, was pasted on filter paper to form a horizontal section and then embedded in optimal cutting temperature (OCT) compound (TissueTek, Miles, Elkhart, IN) at $-80^{\circ} \mathrm{C}$. Tissue segments were sectioned with a cryostat at $6 \mu \mathrm{m}$, and sections were preincubated with Block-Ace (Dainippon Pharmaceutical, Osaka, Japan) to block nonspecific binding of mAbs. The sections were then incubated with hamster (anti-CD11/c) $\mathrm{mAb}$ or rat (anti-c-kit, anti-IL-7R, or anti-Thy-1) $\mathrm{mAb}$ for $30 \mathrm{~min}$ at $37^{\circ} \mathrm{C}$ and rinsed three times with phosphate-buffered saline (PBS), followed by incubation with biotin-conjugated goat anti-hamster IgG $\mathrm{Ab}\left(5 \mu \mathrm{g} \mathrm{ml}^{-1}\right.$; Jackson Immunoreseach Laboratories, West Grove, PA) or goat anti-rat IgG Ab $\left(5 \mu \mathrm{g} \mathrm{ml}^{-1}\right.$; Cedarlane Laboratories Limited, Burlington, Ontario, Canada). In staining with biotinylated antiLy5.2 mAb, the second biotin-conjugated anti-IgG Ab was not used. Subsequently, the sections were washed three times with PBS and then incubated with avidin-biotin peroxidase complexes (Vectastain ABC kit; Vector Laboratories). Histochemical color development was achieved with a Vectastain DAB (3,3' -diaminobenzidine) substrate kit (Vector laboratories, Inc., Burlingame, CA) according to the manufacturer's instructions. Finally, the sections were counterstained with hematoxylin for microscopy. Endogenous peroxidase activity was blocked with $0.3 \% \mathrm{H}_{2} \mathrm{O}_{2}$ and $0.1 \%$ $\mathrm{NaN}_{3}$ in distilled water for $10 \mathrm{~min}$ at room temperature. Tissue sections incubated with either non-immune hamster serum or isotype-matched normal rat IgG showed only minimal background staining. 
Immunofluorescence. The small intestine was longitudinally opened along the mesenteric wall and then the intestine, $\sim 10 \mathrm{~mm}$ in length, was sandwiched between filter paper. Subsequently, tissue segments were immersed in $3 \%$ paraformaldehyde in PBS for $2 \mathrm{~h}$ at $4{ }^{\circ} \mathrm{C}$. After that, the tissues were immersed in $20 \%$ sucrose in PBS overnight at $4{ }^{\circ} \mathrm{C}$. After fixation, tissue segments were pasted on filter paper and then embedded in OCT compound (Tissue-Tek) at $-80^{\circ} \mathrm{C}$. Tissue segments were sectioned with a cryostat $6 \mu \mathrm{m}$, and sections were preincubated with Block-Ace to block nonspecific binding of $\mathrm{mAb}$. The sections were then incubated with anti-c-kit $\mathrm{mAb}$ for $30 \mathrm{~min}$ at $37^{\circ} \mathrm{C}$ and rinsed three times with PBS, followed by incubation with biotinylated goat anti-rat IgG. Subsequently, the sections were incubated with streptavidin-PE (BD Biosciences, San Jose, CA). The stained tissue sections were examined using a Meta Zeiss LSM510 confocal laser scanning inverted microscope (Carl Zeiss, Oberkochen, Germany).

Flow cytometry and cell sorting. Mesenteric lymph nodes and connective tissues were carefully removed from the small intestine; fecal material was flushed from the lumen with PBS, and PPs were then identified and carefully removed from the intestinal wall. Subsequently, CP cells were isolated according to a newly devised method described elsewhere ${ }^{1,4,5}$ and IELs were isolated as described. ${ }^{37}$ In brief, the small intestine was opened longitudinally along the mesenteric wall and mucus and feces were cleared out using filter paper. Subsequently, the intestine, $\sim 10 \mathrm{~mm}$ in length, was pasted on a plastic culture dish. We amputated a 21 -gauge needle exactly at the proximal end of the tapering tip. We then bent the needle in the middle, sharpened its cross-section with the aid of a small electric grinder, i.e., a dental instrument (UA12A; Urawa Kogyo, Saitama, Japan) and finally fitted it on a 1-ml syringe. We located CPs under a transillumination stereomicroscope and isolated a tiny fragment of the small intestine containing one $\mathrm{CP}$ using the needle described above. The tissue segments deprived of a large number of IELs and epithelial cells by the above procedure ${ }^{37}$ were washed two times with Ca- and Mg-free PBS and then incubated with $40 \mathrm{ml}$ of Ca- and Mg-free PBS containing $1 \mathrm{mM}$ EDTA for $30 \mathrm{~min}$ at room temperature with stirring to further remove the remaining IELs and epithelial cells. Next, we isolated lamina proprial lymphocytes from the small intestinal mucosa deprived of IELs and epithelial cells, according to the method described elsewhere. ${ }^{38}$ The isolated CP cells, IELs, and lamina proprial lymphocytes were incubated first with biotinylated $\mathrm{mAb}$ and then with streptavidin-allophycocyanin (BD Biosciences) and PE-conjugated second $\mathrm{mAb}$. IELs were also incubated first with biotinylated anti- $\gamma \delta \mathrm{mAb}$ and then with streptavidin-PE (BD Biosciences) and fluorescein isothiocyanate-conjugated $\mathrm{mAb}$ (anti- $\mathrm{V} \gamma 1$, anti-V $\gamma 4$, or anti- $\mathrm{V} \gamma 7$ ). Stained cells were suspended in Hank's solution without phenol red containing $0.02 \% \mathrm{NaN}_{3}, 2 \%$ heat-inactivated fetal calf serum, and $0.5 \mu \mathrm{g} \mathrm{ml}^{-1}$ propidium iodide and then analyzed using FACSaria with Divasoftware and CellQuest (BD Biosciences). Dead cells were excluded by propidium iodide gating. For three-color analysis of IEL, IELs were incubated first with biotinylated $\mathrm{mAb}$ (anti-CD8 $\beta$ or antiCD4) and then with streptavidin-allophycocyanin. After washing, IELs were counterstained with two combinations of PE-conjugated $\mathrm{mAb}$ (antiTCR $\alpha \beta$ or anti-TCR $\gamma \delta$ ) and fluorescein isothiocyanate-conjugated anti$\mathrm{CD} 8 \propto \mathrm{mAb}$. Lymphoid cells from mice were incubated with anti-Fc $\gamma \mathrm{R}$ II/III mAb (2.4G2; BD Pharmingen) before staining to block nonspecific binding of labeled $\mathrm{mAb}$ to $\mathrm{Fc} \gamma \mathrm{R}$. c-kit ${ }^{+} \mathrm{Lin}^{-} \mathrm{EGFP}^{-}$, c-kit ${ }^{+} \mathrm{Lin}^{-} \mathrm{EGFP}$ low, and c-kit ${ }^{+} \mathrm{Lin}^{-}$EGFPhigh IELs from nu/nu EGFP/ + mice and splenic B $\left(\mathrm{CD} 19^{+}\right)$and $\mathrm{T}\left(\mathrm{CD}^{+}\right)$cells from $\mathrm{B} 6$ mice were sorted by FACSaria.

Semiquantitative reverse transcriptase-PCR analysis of mRNA level. Semiquantitative RT-PCR analysis was performed according to the method described previously. ${ }^{5,11}$ In brief, total RNA was prepared from sorted c-kit ${ }^{+} \mathrm{Lin}^{-} \mathrm{EGFP}^{-}, \mathrm{c}_{-} \mathrm{kit}^{+} \mathrm{Lin}^{-} \mathrm{EGFP}^{\mathrm{low}}$, and c-kit ${ }^{+} \mathrm{Lin}^{-} \mathrm{EGFPhigh}$ IELs of nu/nu EGFP/ + mice as well as sorted splenic B and T cells of B6 mice with an RNeasy Micro kit (Qiagen GmbH, Hilden, Germany), according to the manufacturer's protocol. For the RT-PCR amplifications of serial dilutions of RNA samples with the Qiagen One-Step RT-PCR kit, the reaction was carried out at $50^{\circ} \mathrm{C}$ for $30 \mathrm{~min}$, according to the manufacturer's protocol. Fifteen minutes of denaturation at $95^{\circ} \mathrm{C}$ was included before initiation of PCR cycles for the Qiagen One-Step RT-PCR kit, as it contains a hot-start Tag polymerase. Subsequently, PCR amplification for 35 cycles was performed for $15 \mathrm{~s}$ at $94^{\circ} \mathrm{C}, 30 \mathrm{~s}$ at $60^{\circ} \mathrm{C}$, and $1 \mathrm{~min}$ at $72^{\circ} \mathrm{C}$. The PCR products were run on $2 \%$ agarose gel and visualized by ethidium bromide staining. PCR primers and fragment length of PCR products were as follows: TdT, 5' -ACAGCGAGAAGAGCGGCCAGCAG-3' and 5' CCATGGTTCAATGTAGTCCAGTC-3', 270 bp; ${ }^{39}$ ROR $\gamma \mathrm{t}, 5^{\prime}$-ACCTCC ACTGCCAGCTGTGTGCTGTC- 3 'and $5^{\prime}$-CAAGTTCAGGATGCCTGGTTTC CTC-3' ${ }^{\prime}, 725 \mathrm{bp} ;{ }^{31}$ and EGFP, $5^{\prime}$-GCGAGGGCGATGCCACCTACGGC A-3' and $5^{\prime}$-GGGTGTTCTGCTGGTAGTGGTCGG-3' $450 \mathrm{bp}$. Those of CD3 $\varepsilon$, pre-T $\alpha$, TCRC $\beta 2$, TCRV $\beta 8.1 / 2-C \beta 1 / 2$, TCRJ $\gamma 1-C \gamma 1 / \mathrm{J} \gamma 2-\mathrm{C} \gamma 2$, TCRV $\gamma 7-C \gamma 1$, and $\beta$-actin have been described previously. ${ }^{5,11}$

Statistical analysis. The statistical difference was determined by a two-sided Student's $t$-test.

SUPPLEMENTARY MATERIAL is linked to the online version of the paper at http://www.nature.com/mi

\section{ACKNOWLEDGMENTS}

We thank Dr. B Rocha for many valuable discussions and critical reading of the manuscript and are indebted to Dr. D Littman for the B6 ROR $\gamma \mathrm{tEGFP/EGFP}$ mice. This work was supported in part by a Grant-in-Aid for Creative Scientific Research, the Japan Society for the Promotion of Science (13GS0015), by Special Coordination Funds for Promoting Science and Technology from the Japanese Ministry of Education, Culture, Sports, Science and Technology, by Research on Specific Diseases, Japanese Ministry of Health, Labor and Welfare (H.I.), and by Keio University Special Grant-in-Aid for Innovative Collaborative Research Projects (T.H.). T.N. was a research fellow supported previously by 21 st Century COE Program for Life Science from MEXT and is now supported by Global COE Program for Human Metabolomic Systems Biology from MEXT (headed by M.S.).

\section{DISCLOSURE}

The authors declared no conflict of interest.

C 2008 Society for Mucosal Immunology

\section{REFERENCES}

1. Hamada, H. et al. Identification of multiple isolated lymphoid follicles on the antimesenteric wall of the mouse small intestine. J. Immunol. 168, 57-64 (2002)

2. Lorenz, R.G., Chaplin, D.D., McDonald, K.G., McDonough, J.S. \& Newberry, R.D. Isolated lymphoid follicle formation is inducible and dependent upon lymphotoxin-sufficient B lymphocytes, lymphotoxin $\beta$ receptor, and TNF receptor I function. J. Immunol. 170, 5475-5482 (2003).

3. Kanamori, Y. et al. Identification of novel lymphoid tissues in murine intestinal mucosa where clusters of c-kit ${ }^{+} \mathrm{LL}-7 \mathrm{R}^{+}$Thy $1^{+}$Iymphohemopoietic progenitors develop. J. Exp. Med. 184, 1449-1459 (1996).

4. Saito, H. et al. Generation of intestinal T cells from progenitors residing in gut cryptopatches. Science 280, 275-278 (1998).

5. Suzuki, K. et al. Gut cryptopatches: direct evidence of extrathymic anatomical sites for intestinal T lymphopoiesis. Immunity 13, 691-702 (2000).

6. Rocha, B., Vassalli, P. \& Guy-Grand, D. The $V \beta$ repertoire of mouse gut homodimeric $\alpha$ CD8 ${ }^{+}$intraepithelial T cell receptor $\alpha / \beta^{+}$lymphocytes reveals a major extrathymic pathway of T cell differentiation. J. Exp. Med. 173, 483-486 (1991).

7. Hayday, A., Theodoridis, E., Ramsburg, E. \& Shires, J. Intraepithelial lymphocytes: exploring the third way in immunology. Nat. Immunol. 2, 997-1003 (2001).

8. Klein, J.R. Ontogeny of the Thy-1 ${ }^{-}$, Lyt-2 $2^{+}$murine intestinal intraepithelial Iymphocyte. J. Exp. Med. 164, 309-314 (1986).

9. Guy-Grand, D. et al. Two gut intraepithelial CD8 ${ }^{+}$lymphocyte populations with different $T$ cell receptors: a role for the gut epithelium in $T$ cell differentiation. J. Exp. Med. 173, 471-481 (1991). 
10. Laky, K. et al. Enterocyte expression of interleukin 7 induces development of $\gamma \delta$ T cells and Peyer's patches. J. Exp. Med. 191, 1569-1580 (2000).

11. Oida, T. et al. Role of gut cryptopatches in early extrathymic maturation of intestinal intraepithelial T cells. J. Immunol. 164, 3616-3626 (2000).

12. Onai, N. et al. Pivotal role of CCL25 (TECK)-CCR9 in the formation of gut cryptopatches and consequent appearance of intestinal intraepithelial T lymphocytes. Int. Immunol. 14, 687-694 (2002).

13. Lugering, A. et al. Lymphoid precursors in intestinal cryptopatches express CCR6 and undergo dysregulated development in the absence of CCR6. J. Immunol. 171, 2208-2215 (2003).

14. Nonaka, S. et al. Intestinal $\gamma \delta$ T cells develop in mice lacking thymus, all lymph nodes, Peyer's patches, and isolated lymphoid follicles. J. Immunol. 174, 1906-1912 (2005).

15. Lambolez, F. et al. Characterization of T cell differentiation in the murine gut. J. Exp. Med. 195, 437-449 (2002).

16. Podd, B.S. et al. T cells in cryptopatch aggregates share TCR $\gamma$ variable region junctional sequences with $\gamma \delta$ T cells in the small intestinal epithelium of mice. J. Immunol. 176, 6532-6542 (2006).

17. Maki, K., Sunaga, S. \& Ikuta, K. The V-J recombination of T cell receptor- $\gamma$ genes is blocked in interleukin-7 receptor-deficient mice. J. Exp. Med. 184, 2423-2427 (1996).

18. Eberl, G. \& Littman, D.R. Thymic origin of intestinal $\alpha \beta T$ cells revealed by fate mapping of ROR $\gamma \mathrm{t}^{+}$cells. Science $\mathbf{3 0 5}$, 248-251 (2004).

19. Eberl, G. et al. An essential function for the nuclear receptor ROR $\gamma$ t in the generation of fetal lymphoid tissue inducer cells. Nat. Immunol. 5, 64-73 (2004).

20. Eberl, G. Inducible lymphoid tissues in the adult gut: recapitulation of a fetal developmental pathway? Nat. Rev. Immunol. 5, 413-420 (2005).

21. Rocha, B. Comment on "Thymic origin of intestinal $\alpha \beta$ T cells revealed by fate mapping of ROR $\gamma \mathrm{t}^{+}$cells". Science $\mathbf{3 0 8 , 1 5 5 3 a}$ (2005).

22. Lin, T. et al. CD3 ${ }^{-} \mathrm{CD} 8^{+}$intestinal intraepithelial lymphocytes (IEL) and the extrathymic development of IEL. Eur. J. Immunol. 24, 1080-1087 (1994).

23. Bruno, L., Rocha, B., Rolink, A., von Boehmer, H. \& Rodewald, H.R. Intraand extra-thymic expression of the pre-T cell receptor alpha gene. Eur. J. Immunol. 25, 1877-1882 (1995).

24. Page, S.T. et al. Intestinal intraepithelial lymphocytes include precursors committed to the T cell receptor $\alpha \beta$ lineage. Proc. Natl. Acad. Sci. USA 95, 9459-9464 (1998).

25. Rocha, B. The extrathymic T cell differentiation in the murine gut. Immunol. Rev. 215, 166-177 (2007).
26. Ivanov, I.I. et al. The orphan nuclear receptor ROR $\gamma$ t directs the differentiation program of proinflammatory IL- $17^{+}$Thelper cells. Cell 126, 1121-1133 (2006).

27. Lambolez, F. et al. The thymus exports long-lived fully committed T cell precursors that can colonize primary lymphoid organs. Nat. Immunol. 7, 76-82 (2006).

28. Ishikawa, H. et al. Curriculum vitae of intestinal intraepithelial T cells: their developmental and behavioral characteristics. Immunol. Rev. 215, 154-165 (2007).

29. Finke, D. Fate and function of lymphoid tissue inducer cells. Curr. Opin. Immunol. 17, 144-150 (2005).

30. Villey, I., de Chasseval, R. \& de Villartay, J.P. ROR $\gamma$ T, a thymus-specific isoform of the orphan nuclear receptor ROR $\gamma / T O R$, is up-regulated by signaling through the pre-T cell receptor and binds to the TEA promoter. Eur. J. Immunol. 29, 4072-4080 (1999).

31. Silva-Santos, B., Pennington, D.J. \& Hayday, A.C. Lymphotoxin-mediated regulation of $\gamma \delta$ cell differentiation by $\alpha \beta$ T cell progenitors. Science 307 , 925-928 (2005).

32. Fukuyama, S. et al. Initiation of NALT organogenesis is independent of the IL-7R, LT $\beta R$, and NIK signaling pathways but requires the Id2 gene and CD3 ${ }^{-} \mathrm{CD} 4^{+} \mathrm{CD} 45^{+}$cells. Immunity 17, 31-40 (2002).

33. Harmsen, A. et al. Cutting edge: organogenesis of nasal-associated lymphoid tissue (NALT) occurs independently of lymphotoxin- $\alpha(L T \alpha)$ and retinoic acid receptor-related orphan receptor- $\gamma$, but the organization of NALT is LT $\alpha$ dependent. J. Immunol. 168, 986-990 (2002).

34. Moyron-Quiroz, J.E. et al. Persistence and responsiveness of immunologic memory in the absence of secondary lymphoid organs. Immunity 25, 643-654 (2006).

35. Pabst, O. et al. Cryptopatches and isolated lymphoid follicles: dynamic lymphoid tissues dispensable for the generation of intraepithelial lymphocytes. Eur. J. Immunol. 35, 98-107 (2005).

36. Suzuki, S. et al. Low level of mixing of partner cells seen in extrathymic T cells in the liver and intestine of parabiotic mice: its biological implication. Eur. J. Immunol. 28, 3719-3729 (1998).

37. Fujiura, Y. et al. Development of CD8 $\alpha \alpha^{+}$intestinal intraepithelial T cells in $\beta_{2}$-microglobulin- and/or TAP1-deficient mice. J. Immunol. 156, 2710-2715 (1996).

38. Mega, J. et al. Regulation of mucosal responses by $\mathrm{CD} 4^{+} \mathrm{T}$ lymphocytes: effects of anti-L3T4 treatment on the gastrointestinal immune system. Int. Immunol. 3, 793-805 (1991).

39. Bogue, M., Gilfillan, S., Benoist, C. \& Mathis, D. Regulation of N-region diversity in antigen receptors through thymocyte differentiation and thymus ontogeny. Proc. Natl. Acad. Sci. USA 89, 11011-11015 (1992). 